\title{
The epidemiology of traumatic brain injuries sustained by children under 10 years of age presenting to a tertiary hospital in Soweto, South Africa
}

\author{
V Lack, ${ }^{1}$ BSc, BVSc, MB BCh; P N Fru, ${ }^{2} \mathrm{PhD}$; C van Rensburg, ${ }^{2} \mathrm{MB}$ BCh; K van Rensburg, ${ }^{2} \mathrm{MB}$ BCh; \\ J A Loveland, ${ }^{1}$ MB BCh, FCS (SA), Cert Paed Surg (SA)

\begin{abstract}
${ }^{1}$ Department of Paediatric Surgery, Chris Hani Baragwanath Academic Hospital and Division of General Surgery, School of Clinical Medicine, Faculty of Health Sciences, University of the Witwatersrand, Johannesburg, South Africa

${ }^{2}$ Division of General Surgery, School of Clinical Medicine, Faculty of Health Sciences, University of the Witwatersrand, Johannesburg,
\end{abstract} \\ South Africa
}

Corresponding author: VLack (veredlack@yahoo.com)

\begin{abstract}
Background. Traumatic brain injury (TBI) in the paediatric population is a significant contributor to death and disability worldwide. In sub-Saharan Africa, death and disability from TBI are still superseded by infectious disease. Mechanisms of injury differ by region and socioeconomics, but in general, falls, road traffic collisions (RTCs), being 'struck by/against objects' and non-accidental injuries (NAIs) are responsible for most cases.

Objectives. To: (i) quantify the burden of TBI in terms of demographics, causes and severity; (ii) explore resource utilisation regarding length of stay, computed tomography (CT) brain scan use and multidisciplinary participation; (iii) interrogate possible temporal patterns of injury; and (iv) thus identify potential targets for community-based prevention strategies.

Methods. In a 5-year retrospective review of all children aged $<10$ years admitted with TBI between September 2013 and August 2018 , demographics, date of injury, mechanism of injury, severity of TBI based on the Glasgow Coma Scale, and requirement for a CT brain scan were collected for each patient. Outcomes were reported as discharge, transfer or death. Outcomes for children sustaining isolated TBI were compared with those for children sustaining TBI with polytrauma.

Results. A total of 2153 patients were included, with a mean (standard deviation) age of 4.6 (2.7) years and a male/female ratio of 1.7:1. RTCs were the most frequent cause of injury at $59 \%$ ( $80 \%$ of these were pedestrian-vehicle collisions), followed by falls at $24 \%$. Mild TBIs accounted for $87 \%$ of admissions, moderate injuries for $6 \%$, and severe injuries for $7 \%$. Polytrauma was associated with increased severity of TBI. The cohort had a $2.3 \%$ mortality. NAIs accounted for $6 \%$ of injuries and carried a $4 \%$ mortality. The median (interquartile range) duration of hospitalisation was 1 ( 1 - 3) days, ranging from <24 hours to 132 days. CT scans were performed on $43 \%$ of admitted patients, and $48 \%$ of patients had consultations with another medical or allied medical discipline. Injuries were more frequent during the summer months and over weekends. Infants aged $<1$ year were identified as a group particularly vulnerable to injury, specifically NAI.

Conclusions. Paediatric TBI was demonstrated to be a resource-intensive public health concern. From the results, we identified potential primary prevention targets that could perhaps be incorporated into broader community-based intervention programmes. We also identified a need to study long-term consequences of mild TBI further in our paediatric population.
\end{abstract}

S Afr Med J 2021;111(8):789-795. https://doi.org/10.7196/SAMJ.2021.v111i8.15553

Traumatic brain injury (TBI) in the paediatric population is a significant contributor to death and disability worldwide. It is estimated that every year $>3$ million children are affected by TBI globally. Incidence rates vary between countries, with the lowest rates in northern European countries (Sweden 12 per 100 000) and the highest rate reported from Australia (280 per 100 000). The term TBI encompasses a broad range of injuries to the skull and underlying brain resulting from external forces applied to the head. ${ }^{[1,2]}$ In the paediatric population in sub-Saharan African countries, death and disability from TBI are still superseded by infectious disease. ${ }^{[3]}$ Mechanisms of injury differ by region and are affected by socioeconomic factors, but in general, falls, road traffic collisions (RTCs), being 'struck by/against objects' and assault/nonaccidental injury (NAI) are responsible for the majority of cases. ${ }^{[1,-8]}$ Severe TBI can result in long-term disability, placing a significant burden on families, caregivers and the healthcare system. ${ }^{[5,6]}$ Children have the added impact of long-term sequelae from injuring the developing brain, with recent recognition that even mild TBI can cause persistent neurocognitive and behavioural alterations. ${ }^{[9-11]}$

Epidemiological studies investigating injury patterns, risk factors and resource use for paediatric TBI have been conducted throughout the world. ${ }^{[3,5,12,13]}$ In South Africa (SA), where a high rate of traumatic injury is well documented, children have received little attention compared with their adult counterparts. ${ }^{[1,15]}$ There have only been a few SA hospital-based studies examining paediatric TBI, hence the motivation for the present study. ${ }^{[4,14,16]}$

Chris Hani Baragwanath Academic Hospital (CHBAH) in Soweto, Gauteng Province, is a tertiary-level institution serving an area of $200 \mathrm{~km}^{2}$ inhabited by 1.7 million people, of whom $25.7 \%$ are children aged $<14$ years. ${ }^{[17]}$ The Department of Paediatric Surgery at CHBAH addresses the general surgical needs of all children admitted up to 10 years of age. This age cut-off was arbitrarily set in the 1990s owing to staffing and resource constraints (Prof. K Lakhoo, personal communication, 8 October 2020). Paediatric trauma admissions are 
a daily occurrence at $\mathrm{CHBAH}$, yet there are no formal statistics on these patients.

\section{Objectives}

This 5-year retrospective review of prospectively accumulated data sought to address this gap. It is hoped that the resulting information will aid in guiding primary prevention strategies in our region, and allow for better resource allocation in our institution.

\section{Methods}

On arrival at $\mathrm{CHBAH}$, all injured paediatric patients presenting to the trauma emergency department are assessed, resuscitated as per advanced trauma life support (ATLS) principles, and stabilised. They are further cared for by the paediatric surgery service, with the exception of severe isolated head injuries requiring neurosurgical intervention.

\section{Study population}

All children aged $<10$ years admitted to $\mathrm{CHBAH}$ with a diagnosis of acute TBI between September 2013 and August 2018 within 24 hours of injury were included in the study. Patients with underlying medical conditions such as febrile seizures or meningitis who were erroneously admitted as TBI were excluded from the study.

\section{Data collection}

Demographic information, mechanism of injury, severity of injury based on the Glasgow Coma Scale (GCS), and requirement for a computed tomography (CT) brain scan (and results) were collected for each patient. Outcomes were reported as discharge, transfer to another department or death. Outcomes for children sustaining isolated TBI were compared with those for children sustaining polytrauma in addition to TBI.

Patients were assigned to one of the following major categories of injury: RTCs (including where the child is injured as a pedestrian or a passenger inside the vehicle, or by falling from a moving vehicle), falls (including falls from a height with distance fallen $>1.5 \mathrm{~m}$, and falling off furniture), being 'struck by/against objects', non-accidental injuries (NAIs), penetrating injuries, other and unknown. The category of 'unknown' mechanism represented patients with unwitnessed mechanism of injury. The category of 'other' included injuries sustained from a school stampede, and other infrequent mechanisms.

Patients were assigned to one of three TBI severity categories based on ATLS principles as mild (GCS 13 - 15), moderate (GCS 9 - 12) or severe (GCS $3-8$ ) head injury. For data analysis, files were categorised by age group as follows: infants ( 0 - 12 months), toddlers ( 1 - 3 years), preschoolers (4- 6 years), and school-going children (7 - 10 years). A CT brain scan was considered abnormal if acute intracranial or calvarial pathology was identified. Soft-tissue changes or incidental findings not related to trauma were not considered significant.

\section{Statistical analysis}

All data were loaded onto an Excel spreadsheet, version 2015 14026.20308 (Microsoft Corp., USA) and analysed using Stata version 15.1 2014 LP (StataCorp, USA) software. Categorical variables were described with frequencies, percentages and $95 \%$ confidence intervals (CIs) where necessary. Continuous variables were described using medians and interquartile ranges. Where appropriate, statistical significance was accepted as relevant if $p<0.05$.

\section{Ethical approval}

Ethical approval was obtained from the University of the Witwatersrand Human Research Ethics Committee (ref. no. M160507).

\section{Results}

During the study period, 2286 children aged $<10$ years were admitted with a diagnosis of TBI. Eighty-five files contained insufficient data, 34 patients presented $>24$ hours after the occurrence of the injury, and 14 patients were misdiagnosed; 133 patients were therefore excluded from the study, with a final total study population of 2153 patients.

The mean (standard deviation) age of the study sample was 4.6 (2.7) years. Infants accounted for $12.1 \%$ (95\% CI $10.7-13.5)$ of admissions, toddlers for $31.5 \%$ (95\% CI 29.5 - 33.5), preschoolers for $33.6 \%$ (95\% CI 31.6 - 35.6), and children aged 7 - 10 years for $22.8 \%$ (95\% CI 21.0 - 24.6). Overall, more than half the children admitted (55\%; 95\% CI 47.0 - 51.3) were aged $<5$ years. Males made up 63\% ( $n=1350 / 2153$ ) of the cohort. In the infant age group, the male/ female ratio was 1.3:1, climbing to 2.2:1 for the oldest age group. The overall male/female ratio was 1.7:1 (Table 1).

\section{Mechanism of injury}

RTCs were the most frequently reported category of injury, accounting for 59\% ( $n=1268 / 2153$ ) of all injuries sustained (Table 1). Pedestrians incurred $80 \%(n=1015 / 1268)$ of injuries in this category and comprised almost half of the total admissions (47\%). Motor vehicle collisions in which children were occupants of the vehicle contributed to $17.5 \%$ ( $n=221 / 1268$ ) of RTCs. In addition, $2.5 \%$ of children ( $n=32 / 1268$ ) were injured by falling out of moving vehicles. Falls followed as the second most significant category of injury at $24 \%$ ( $n=521 / 2153)$, with infants mostly falling off furniture indoors and older children falling while playing outdoors (Figs 1 and 2). Injuries were sustained outdoors for $81 \%$ of admissions. Falls from a height accounted for $12 \%(n=61 / 521)$ of this category, mostly falling from trees, falling off one-storey structures or falling off perimeter walls. Males were strongly represented in this subgroup, with a male/female ratio of 2.8:1.

In the NAI category, assault accounted for $4 \%(n=87 / 2153)$ of the cohort, and males were affected almost three times more than females. Infants were the most frequently affected age group, at $23 \%$ $(n=20 / 87)$. Forty-one children were reportedly dropped, of whom $63 \%(n=26 / 41)$ were infants. Five children in this subcategory were injured after being thrown in the air, the youngest of these only 1 month of age. Altogether, in the NAI category, infants comprised $36 \%(n=46 / 128)$ of the cohort. The group of children 'struck by/ against objects' made up 5.4\% $(n=116 / 2153)$ of the cohort. Of these injuries, $17 \%(n=20 / 116)$ were caused by indoor items such as television sets, shelving and door-frames falling on children. The rest of these injuries $(83 \% ; n=96 / 116)$ were incurred outdoors, as a result of structural items such as poles, concrete slabs and perimeter fence entrance gates falling on children. Children aged between 1 and 6 years of age were the most frequently injured here. There were 10 TBIs due to penetrating injuries. These included 5 dog bite injuries ( 1 resulting in death), 1 stab injury in a 5 -year-old, and 4 firearm injuries.

\section{Injury severity}

Isolated head injuries were sustained by $73 \%(n=1582 / 2153)$ of patients, of which $92 \%$ ( $n=1462 / 1582)$ resulted in mild TBI. In contrast, polytrauma patients accounted for $27 \%(n=571 / 2153)$ of admissions, of whom $74 \%(n=422 / 572)$ had mild TBI (Table 2). Polytrauma in combination with TBI, although less common, was associated with increased injury severity compared with isolated TBI (Fig. 3).

Stratifying mortality by injury severity, mild head injuries carried a $0.4 \%$ mortality, moderate head injuries a $4 \%$ mortality and severe 
Table 1. Summary of demographics and outcomes by cause of traumatic brain injury

\begin{tabular}{lllllll}
\hline Cause & $\boldsymbol{n}(\%)$ & M/F ratio & $\begin{array}{l}\text { Age (years), } \\
\text { median (IQR) }\end{array}$ & $\begin{array}{l}\text { Admission (days), } \\
\text { median (IQR) }\end{array}$ & Isolated HI, $\boldsymbol{n}$ (\%) & Mortality, $\boldsymbol{n}$ (\%) \\
\hline RTC & 1268 & $1.6: 1$ & $5.4(3.4-7.3)$ & $1(1-3)$ & $799(63)$ & $36(2.8)$ \\
$\quad$ Pedestrians & $1015(80)$ & $1.7: 1$ & $5.6(3.6-7.3)$ & $1(1-3)$ & $634(62)$ & $31(3.1)$ \\
Passengers & $221(17.5)$ & $1: 1$ & $4.6(2.5-6.6)$ & $2(1-5)$ & $135(61)$ & $5(2.3)$ \\
Fall from vehicle & $32(2.5)$ & $1.9: 1$ & $6.9(5.8-8.2)$ & $1(1-2)$ & $30(94)$ & 0 \\
Fall & 521 & $1.7: 1$ & $2.3(0.9-5)$ & $1(1-2)$ & $490(94)$ & $1(0.2)$ \\
While playing & $321(61)$ & $1.8: 1$ & $3.3(1.3-5.5)$ & $1(1-1)$ & $305(95)$ & $1(0.3)$ \\
Off furniture & $139(27)$ & $1.3: 1$ & $0.9(0.6-1.6)$ & $1(1-2)$ & $133(96)$ & 0 \\
Fall from height & $61(12)$ & $2.8: 1$ & $4.8(2-6.6)$ & $1.5(1-2)$ & $50(82)$ & 0 \\
NAI & 128 & $2: 1$ & $2(0.5-5.5)$ & $2(1-6)$ & $102(80)$ & $5(3.9)$ \\
Assault & $87(68)$ & $2.7: 1$ & $4.3(1.1-6.5)$ & $3(2-8)$ & $63(72)$ & $5(5.7)$ \\
Dropped & $41(32)$ & $1: 1$ & $0.5(0.2-1.3)$ & $1(1-2)$ & $39(95)$ & 0 \\
Struck by/against object & 116 & $1.9: 1$ & $3.9(2.3-65.5)$ & $1(1-2)$ & $91(79)$ & $3(2.6)$ \\
Indoor injury & $20(17)$ & $2.3: 1$ & $2.9(1.9-4.3)$ & $1(1-2)$ & $15(75)$ & 0 \\
Outdoor fixture & $17(15)$ & $1.8: 1$ & $4.3(3.2-6.8)$ & $1(1-2)$ & $15(88)$ & 0 \\
$\quad$ Perimeter gate & $79(68)$ & $1.8: 1$ & $4.3(2.3-6)$ & $1(1-2)$ & $62(78)$ & $3(4.9)$ \\
Penetrating injury & $10(0.5)$ & $2.3: 1$ & $2.4(2.3-4.9)$ & $1(0.25-3.75)$ & $4(40)$ & $1(10)$ \\
Other and unknown & $110(5)$ & $1.9: 1$ & $3.5(1.1-6.3)$ & $1(1-2)$ & $95(86)$ & $4(3.6)$ \\
Total & 2153 & $1.7: 1$ & $4.5(2.3-6.7)$ & $1(1-2)$ & $1581(73)$ & $50(2.3)$ \\
M/F = male/female; IQR = interquartile range; $\mathrm{HI}=$ head injury; RTC = road traffic collision; NAI = non-accidental injury. & &
\end{tabular}

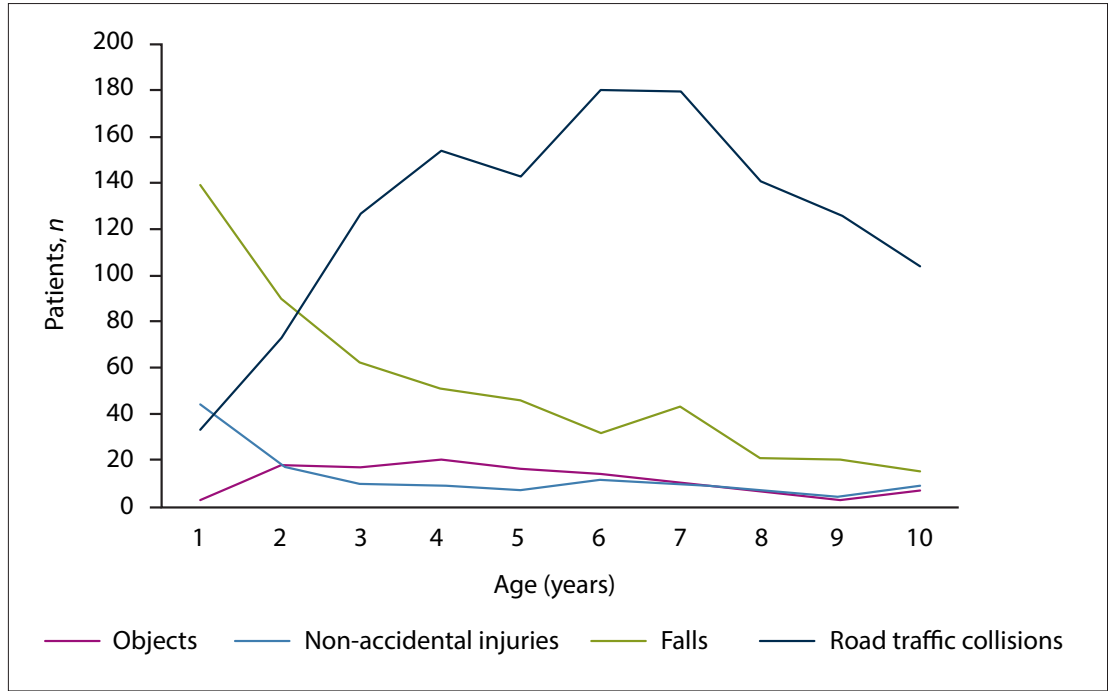

Fig. 1. Frequency of traumatic brain injury type with increasing age.

head injuries the highest mortality of $27 \%$ (Table 2). Moving from one severity grade to the next therefore conferred a several-fold increase in mortality. The infant age group had a statistically significant $(p<0.001)$ increased vulnerability to severe head injuries, with associated mortality of $55 \%$ $(n=6 / 11)$ compared with $24 \%(n=32 / 131)$ for the rest of the cohort.

\section{CT brain scanning practices}

CT brain scans were performed on 933 patients. There were $483 \mathrm{CT}$ scans with reported pathological findings. Of the 261 patients admitted aged $<1$ year, $44 \%$ $(n=114 / 261)$ underwent CT brain scans, of which $67.5 \%(n=77 / 114)$ revealed pathology. injuries was 2.4 days (range $0.5-67$ ), in contrast to 7.2 days (range 1 - 132) for patients with polytrauma with associated TBI. Overall mortality for the cohort was $2.3 \%(n=50 / 2153)$. RTCs were responsible for $72 \%(n=36 / 50)$ of deaths.

All children who sustained NAIs and those with injuries suggestive of unintentional neglect (infants falling off furniture, children falling out of moving vehicles) were referred on to in-house social workers. All patients with positive CT scan findings ( $n=483 / 2153$ ) had consultations with the neurosurgery service, but only $2.5 \%$ required takeover of management. Patients who were admitted for $>2$ days $(n=571 / 2153)$ were additionally assessed by the occupational therapists, physiotherapists and dieticians.

\section{Temporal injury trends}

Various temporal patterns were noted in this study. Weekend days incurred the most admissions. A decrease in the frequency of falls and RTCs was noted during winter months, but increased during summer months and school holiday periods. From the start of the study period in 2013 there was an annual decline in admissions, followed by steady increases after 2016 (Fig. 4).

\section{Discussion}

Regional epidemiological studies such as this one facilitate the description of injuries peculiar to local environments. In the UK, results of the Confidential Enquiry performed in 2014 assisted in the revision of the National Institute for Health and 


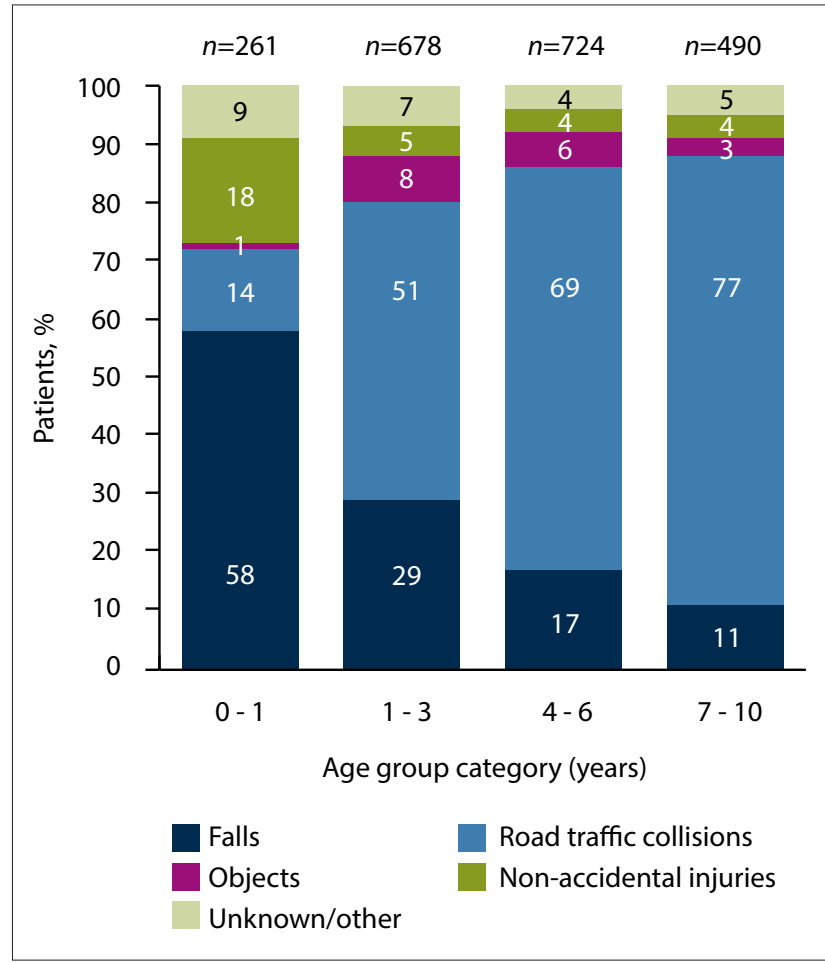

Fig. 2. Proportion of traumatic brain injury frequency by age group category.

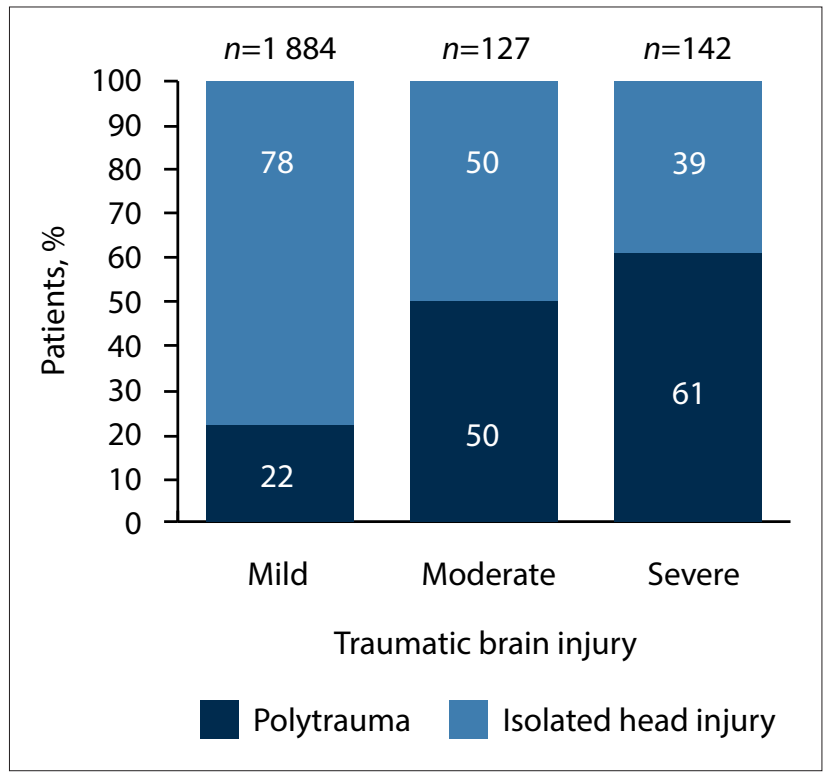

Fig. 3. Correlation between traumatic brain injury severity and polytrauma v. isolated head injury.

Care Excellence (NICE) guidelines for paediatric head injuries. ${ }^{[5]}$ An SA-based study from 2007 reported that the major risk factors for TBI included extremes of age, male gender and low socioeconomic status. ${ }^{[7]}$ The implication that young children from impoverished environments are more vulnerable to trauma was paralleled in our findings, as well as in studies from abroad. ${ }^{[18]}$

Buitendag et al. ${ }^{[14]}$ summarised seven studies between 1984 and 2014 pertaining to paediatric TBI in SA and compared these with their own data. To date, reports from Red Cross War Memorial Children's Hospital in Cape Town and the Pietermaritzburg Hospital Complex account for the bulk of published studies. ${ }^{[4,14,15]}$ Publications

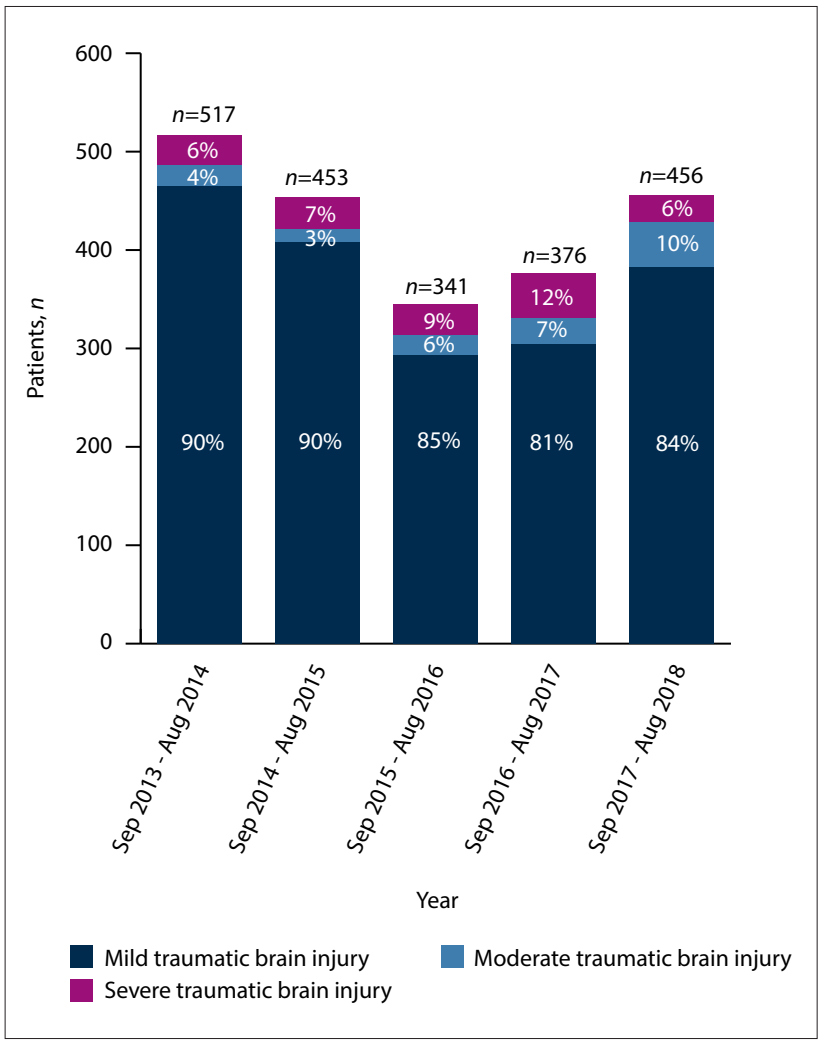

Fig. 4. Annual incidence of traumatic brain injury by severity of injury, September 2013 - August 2018 (date of admission not known for 8 patients).

that focus on TBI in the adult population of Gauteng exist, but the paediatric TBI population of Soweto has not been comprehensively described. ${ }^{[7,8,19]}$

In our cohort, males incurred injuries more frequently than females. This gender disparity is documented almost ubiquitously both locally and internationally. ${ }^{[1,5,6,20]}$ For falls from a height, males were also more prevalent, with a male/female ratio of $2.8: 1$, perhaps reflecting increased risk-taking behaviour of boys. ${ }^{[21]}$

Similar to other low- and middle-income countries (LMICs), pedestrian-vehicle collisions were the dominant cause for admissions, contrasting with higher-income countries, where falls occurred with greater frequency. ${ }^{[1,18,22]}$ Injuries reported in the present study most frequently occurred outdoors, in contrast to many other studies reporting injuries occurring more frequently in the home or while at school. ${ }^{[1,4,5,23]}$ This finding may be a reflection of the socioeconomics of the region: children play outdoors in the absence of suitable supervised recreational areas, walk (sometimes long distances) to school without adult supervision, and are often left at home alone while caregivers are at work.

There is mounting evidence that behavioural factors predispose children to pedestrian-vehicle collisions. The cognitive process of interpreting traffic cues and having adequate psychomotor skills to act appropriately may not be sufficiently developed in children aged $<10$ years. A significant number of RTCs are reportedly due to acts of 'darting out' into streets or 'dashing across intersections. ${ }^{\text {[24] }}$ This impulsive decision-making may predispose younger children to the higher incidence of pedestrian-vehicle collisions as noted in this study. Observations demonstrating that impulsive behaviour is normal for children aged $<10$ years bring into question the efficacy of child-directed education in this age group and motivate for added awareness programmes involving driver behaviour. Infrastructure 
Table 2. Effects of traumatic brain injury severity on presentation, CT scanning practices and outcomes

\begin{tabular}{|c|c|c|c|c|}
\hline Parameter & Mild TBI (GCS 13 - 15) & Moderate TBI (GCS 8 - 12) & Severe TBI (GCS 3 - 7) & Total \\
\hline Total admissions, $n(\%)$ & $1884(87)$ & $127(6)$ & $142(7)$ & 2153 \\
\hline $0-12$ months & $245(94)$ & $5(2)$ & $11(4)$ & 261 \\
\hline $1-3$ years & $583(86)$ & $48(7)$ & $47(7)$ & 678 \\
\hline $4-6$ years & $630(87)$ & $43(6)$ & $51(7)$ & 724 \\
\hline $7-10$ years & $426(87)$ & $31(6.3)$ & $33(6.7)$ & 490 \\
\hline Isolated HI, $n(\%)$ & $1462(78)$ & $64(50)$ & $56(39)$ & 1582 \\
\hline Polytrauma, $n(\%)$ & $422(22)$ & $63(50)$ & $86(61)$ & 571 \\
\hline \multicolumn{5}{|l|}{ Gender, $n(\%)$ : } \\
\hline Male & $1170(87)$ & $85(6)$ & $95(7)$ & 1350 \\
\hline Female & $714(89)$ & $42(5)$ & $47(6)$ & 803 \\
\hline $\mathrm{M} / \mathrm{F}$ ratio & $1.6: 1$ & $2: 1$ & $2: 1$ & $1.7: 1$ \\
\hline \multicolumn{5}{|l|}{ Mechanism of injury, $n(\%)$} \\
\hline RTC & $1059(83)$ & $100(8)$ & $109(9)$ & 1268 \\
\hline Fall & $493(95)$ & $13(2)$ & $15(3)$ & 521 \\
\hline NAI & $118(92)$ & $3(2)$ & $7(6)$ & 128 \\
\hline Struck by/against object & $104(90)$ & $6(5)$ & $6(5)$ & 116 \\
\hline Penetrating injury & $6(60)$ & $3(30)$ & $1(10)$ & 10 \\
\hline Other/unknown & $104(94.5)$ & $2(1.8)$ & $4(3.6)$ & 110 \\
\hline CT performed, $n(\%)$ & $676(36)$ & $126(99)$ & $132(93)$ & 934 \\
\hline $0-12$ months & $100(41)$ & $5(100)$ & $9(82)^{*}$ & 114 \\
\hline $1-3$ years & $187(32)$ & $47(97)^{\dagger}$ & $46(97)$ & 280 \\
\hline $4-6$ years & $233(36)$ & $43(100)$ & $47(95)^{\ddagger}$ & 323 \\
\hline $7-10$ years & $156(36)$ & $31(100)$ & $30(91)^{\varsigma}$ & 217 \\
\hline Abnormal CT result, $n(\%)$ & $278(41)$ & $80(63)$ & $125(95)$ & 483 \\
\hline $0-12$ months & $65(65)^{9}$ & $3(60)$ & $9(100)$ & 77 \\
\hline $1-3$ years & $68(32)^{9}$ & $26(56)$ & $44(96)$ & 138 \\
\hline $4-6$ years & $73(36)^{1}$ & $26(53)^{* *}$ & $46(93)$ & 145 \\
\hline $7-10$ years & $72(41)^{\dagger+}$ & $25(79)$ & $26(92)$ & 123 \\
\hline Mortality, $n(\%)$ & $7(0.4)$ & $5(4)$ & $38(27)$ & 50 \\
\hline \multicolumn{5}{|l|}{ Age group } \\
\hline $0-12$ months & $1(0.4)$ & 0 & $6(55)$ & 7 \\
\hline $1-3$ years & $2(0.5)$ & $4(11)$ & $12(23)$ & 18 \\
\hline $4-6$ years & $3(0.2)$ & 0 & $12(26)$ & 15 \\
\hline $7-10$ years & $1(0.5)$ & $1(2)$ & $8(25)$ & 10 \\
\hline \multicolumn{5}{|l|}{ Isolated $\mathrm{HI}$ v. polytrauma } \\
\hline Isolated $\mathrm{HI}$ & $1(2)$ & $2(4)$ & $12(24)$ & $15(30)$ \\
\hline Polytrauma & $6(12)$ & $3(6)$ & $26(52)$ & $35(70)$ \\
\hline Admission (days), median (IQR), range & $1(1-3), 0.5-67$ & $5(2-11), 0.5-61$ & $11(1-20), 0.5-132$ & $1(1-3), 0.5-132$ \\
\hline
\end{tabular}

modification such as traffic calming structures in high-risk areas, including near schools and in residential areas, may offer some reprieve.

In keeping with other LMICs, injuries due to precarious household infrastructure were common. ${ }^{[7,25]}$ NAI presents a serious concern, as this category carried a $4 \%$ mortality (double that of the entire cohort). Children under a year of age were most frequently affected by NAI, a finding paralleled in other studies. ${ }^{[5,6,26]}$

The need to identify a clinically important injury in mild TBI patients must be balanced against the risk of unnecessary exposure to ionising radiation from CT brain scans. ${ }^{[27,28]}$ Internationally, various algorithms have been developed to help address this. ${ }^{[29]}$ We reported a
CT brain scanning rate of $36 \%$ for mild TBI, of which $41 \%$ identified pathology. Owing to resource constraints in our institution, children were frequently admitted for observation and escalated to a CT scan if the need arose. These are conservative figures compared with higher-income countries; ${ }^{[30,31]}$ however, for this cohort, this strategy did not incur adverse outcomes.

The decrease in TBI admissions in 2015 - 2016 may have occurred for several reasons. The most recent regional population census reported a decrease in population numbers and birth rates for the area during that period. ${ }^{[17]}$ Simultaneously, a primary-level hospital was opened in Soweto in 2014, diverting minor injuries from CHBAH. The steady increase in TBI admissions that followed 
from 2016 may reflect a broader cyclical population pattern in the region, a recovering population growth, or the possibility that the new primary-level institution had become saturated. An increase in RTCs was noted in the summer months and over periods of school holidays. As in other reports, weekend periods incurred higher admission rates. With the exception of NAI, which was consistently reported throughout the year, the temporal pattern in paediatric TBI noted here mirrors previously reported seasonal variability in injury patterns in Soweto. ${ }^{[32]}$

Children under a year of age are completely dependent on their caregivers. Caregivers in turn may not adapt their level of supervision to the child's evolving motor development. Infants are therefore vulnerable to falls from surfaces (furniture) that they are placed on. They are more likely than older children to be dropped by caregivers and siblings, and carry a higher risk of NAI. Infants with mild TBI incur higher rates of CT-positive pathology, and their risk of mortality in severe TBI is significantly increased compared with older children. Perhaps primary injury prevention strategies for this age group can be integrated into educational programmes aimed at mothers attending antenatal clinics and caregivers at well-baby clinics.

It is widely accepted that mild TBI can result in long-term neurocognitive sequelae. ${ }^{[10,11,33]}$ To assess this in the $\mathrm{CHBAH}$ catchment area, we undertook a collaborative prospective study to assess neurocognitive abilities of mildly head-injured children compared with age-matched uninjured children from the same community. Together with the University of the Witwatersrand psychology department and in association with Oxford University, the THINK trial (Traumatic Head Injury: Neurocognitive assessment in Kids) was initiated, based on the population represented in this cohort. Preliminary reports suggest that elements such as speed of processing abilities may be affected following mild TBI, which can have a knock-on effect with regard to future cognitive development and scholastic capabilities, creating further difficulties in the lives of already marginalised children.

\section{Study limitations}

The study was a retrospective analysis of information contained in a database and supplemented by case files. Because of language barriers and young age of children, mechanism of injury could not be identified for 85 patients, resulting in some attrition of data. The study inevitably excludes children who died on the scene from their injuries, and patients who may have been seen by feeder hospitals and clinics and managed there. The cut-off admission age was 10 years, which is not representative of the paediatric population, so it is difficult to make comparisons with findings from other national centres.

\section{Conclusions}

Paediatric TBI was demonstrated to be a resource-intensive public health concern. Increased vulnerability of infants to TBI was identified, and the prevalence of RTCs was highlighted as a necessary target for primary prevention. Antenatal clinics, schools and local clinics could be considered as points of contact for this purpose. Further research into possible primary prevention solutions specific to Soweto is needed. We hope that the results from the THINK study will identify modifiable targets for early rehabilitation to curb longterm sequelae of mild TBI.

Declaration. The research for this study was done in partial fulfilment of the requirements for VL's MMed (Paediatric Surgery) degree at the University of the Witwatersrand.
Acknowledgements. The authors acknowledge the contributions of Mr D J Lack, Mr R Blumenow and Dr M Close.

Author contributions. VL conceptualised the study, designed the study, collected, analysed and interpreted data, and drafted the manuscript, PNF assisted with study design, data analysis and critical revision of the manuscript, CvR assisted in data collection and management and manuscript review, KvR assisted in data collection and management and manuscript review, and JAL contributed to conceptualisation and design of the study, and critical review of the manuscript. All the authors approved the final manuscript.

Funding. None.

Conflicts of interest. None.

1. Dewan MC, Mummareddy N, Wellons JC III, Bonfield CM. Epidemiology of global pediatric traumatic brain injury: Qualitative review. World Neurosurg 2016;91:497-509. https://doi.org/10.1016/j. wneu.2016.03.045

2. World Health Organization. The global burden of disease 2004. Geneva: WHO, 2004:146. https://www:

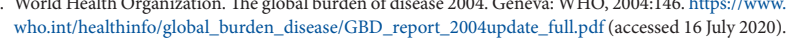
3. Wdoh D, Adeyemo A. Traumatic brain injuries in children: A hospital-based study in Nigeria. Afr J 3. Udoh D, Adeyemo A. Traumatic brain injuries in children: A hospital-based
Paediatr Surg 2013;10(2):154-159. https://doi.org/10.4103/0189-6725.115043

4. Lalloo $R$, van As AB. Profile of children with head injuries treated at the trauma unit of Red Cross War Memorial Children's Hospital, 1991 - 2001: Short report. S Afr Med J 2004;94(7):544-546.

5. Trefan L, Houston R, Pearson G, et al. Epidemiology of children with head injury : A national overview. Arch Dis Child 2016;101(6):527-532. https://doi.org/10.1136/archdischild-2015-308424

6. Shao J, Zhu H, Yao H, et al. Characteristics and trends of pediatric traumatic brain injuries treated at a large pediatric medical center in China, 2002 - 2011. PLoS ONE 2012;7(12):5-12. https://doi. org/10.1371/journal.pone.0051634

7. Norman R, Matzopoulos R, Groenewald P, Bradshaw D. The high burden of injuries in South Africa. Bull World Health Organ 2007;85(9):695-702. https://doi.org/10.2471/blt.06.037184

8. Naidoo D. Traumatic brain injury: The South African landscape. S Afr Med J 2013;103(9):613-614. https://doi.org/10.7196/SAMJ.7325

9. Gronwall D, Wrightson P, McGinn V. Effect of mild head injury during the preschool years. J Int Neuropsychol Soc 1997;3(6):592-597. https://doi.org/10.1017//1355617797005924

10. Li L, Liu J. The effect of pediatric traumatic brain injury on behavioral outcomes: A systematic review. . Li L, Liu J. The effect of pediatric traumatic brain injury on behavioral outcomes: A systematic
Dev Med Child Neurol 2013;55(1):37-45. https://doi.org/10.1111/j.1469-8749.2012.04414.x

11. Schwartz L, Taylor HG, Drotar D, Owen K, Wade SL, Stancin T. Long-term behavior problems Schwartz L, Taylor HG, Drotar D, Owen K, Wade SL, Stancin T. Long-term behavior problems
following pediatric traumatic brain injury: Prevalence, predictors, and correlates. J Pediatr Psychol 2003;28(4):251-263. https://doi.org/10.1093/jpepsy/jsg013

12. Robertson DB, Mcconnel EC, Green S. Charges associated with pediatric head injuries: A five year retrospective review of 41 pediatric hospitals in the US. J Inj Violence Res 2013;5(1):51-60. https:// doi.org/10.5249/jivr.v5i1.205

13. Kim HB, Kim DK, Kwak YH, et al. Epidemiology of traumatic head injury in Korean children. J Korean Med Sci 2012;27(4):437-442. https://doi.org/10.3346/jkms.2012.27.4.438

14. Buitendag JJP, Kong VY, Bruce JL, Laing GL, Clarke DL, Brysiewicz P. The spectrum and outcome of paediatric traumatic brain injury in KwaZulu-Natal Province, South Africa, has not changed over the last two decades. S Afr Med J 2017;107(9):777-780. https://doi.org/10.7196/SAMJ.2017.v107i9.12394

15. Herbert HK, van As AB, Bachani AM, et al. Patterns of pediatric injury in South Africa : An analysis of hospital data between 1997 and 2006. J Trauma Acute Care Surg 2012;73(1):168-174. https://doi. org/10.1097/ta.0b013e31824d67c3

16. Schrieff LE, Thomas KGF, Dollman AK, Rohlwink UK, Figaji AA. Demographic profile of severe traumatic brain injury admissions to Red Cross War Memorial Children's Hospital, 2006 - 2011. S Afr Med J 2013;103(9):616-620. https://doi.org/10.7196/SAMJ.7137

17. Statistics South Africa. Provincial Profile Gauteng: Community Survey 2016. Report number 03-01-09. Statistics South Africa. Provincial Profile Gauteng: Community Survey 2016. Report number 03-01-09.
http://cs2016.statssa.gov.za/wp-content/uploads/2018/07/Gauteng.pdf (accessed 22 November 2019).

18. Laftamme L, Hasselberg M, Burrows S. 20 years of research on socioeconomic inequality and children's . Laflamme L, Hasselberg M, Burrows S. 20 years of research on socioeconomic inequality and children's
unintentional injuries - understanding the cause-specific evidence at hand. Int J Pediatr 2010;819687. unintentional injuries - understanding
https://doi.org/10.1155/2010/819687

19. Seedat M, van Niekerk A, Jewkes R, Suffla S, Ratele K. Violence and injuries in South Africa: Prioritising an agenda for prevention. Lancet 2009;374(9694):1011-1022. https://doi.org/10.1016/ s0140-6736(09)60948-x

20. Araki T, Yokota H, Morita A. Pediatric traumatic brain injury: Characteristic features, diagnosis, and management. Neurol Med Chir 2017;57(2):82-93. https://doi.org/10.2176/nmc.ra.2016-0191

21. Morrongiello BA, Rennie $\mathrm{H}$. Why do boys engage in more risk taking than girls? The role of attributions, beliefs, and risk appraisals. J Pediatr Psychol 1998;23(1):33-43. https://doi.org/10.1093/ jpepsy/23.1.33

22. Burrows $\mathrm{P}$, Trefan L, Houston R, et al. Head injury from falls in children younger than 6 years of age. Arch Dis Child 2015;100(11):1032-1037. https://doi.org/10.1136/archdischild-2014-307119

23. Zhu H, Gao Q, Xia X, Xiang J, Yao H, Shao J. Clinically-important brain injury and CT findings in pediatric mild traumatic brain injuries: A prospective study in a Chinese reference hospital. Int $J$ pediatric mild traumatic brain injuries: A prospective study in a Chinese reference hosp
Environ Res Public Health 2014;11(4):3493-3506. https://doi.org/10.3390/ijerph110403493

24. Stevenson M, Sleet D, Ferguson R. Preventing child pedestrian injury: A guide for practitioners. Am J Stevenson M, Sleet D, Ferguson R. Preventing child pedestrian injury: A guide
Lifestyle Med 2015;9(6):442-450. https://doi.org/10.1177/1559827615569699

25. Weimann A, Oni T. A systematised review of the health impact of urban informal settlements and Weimann A, Oni T. A systematised review of the health impact of urban informal settlements and
implications for upgrading interventions in South Africa, a rapidly urbanising middle-income country. Int J Environ Res Public Health 2019;16(19):1-17. https://doi.org/10.3390/ijerph16193608

26. Keenan HT, Runyan DK, Marshall SW, et al. A population-based study of inflicted traumatic brain injury in young children. JAMA 2003;290(5):621-626. https://doi.org/10.1001/jama.290.5.621

27. Kuppermann N, Holmes JF, Dayan PS, et al. Identification of children at very low risk of clinicallyimportant brain injuries after head trauma: A prospective cohort study. Lancet 2009;374(9696):11601170. https://doi.org/10.1016/S0140-6736(09)61558-0

28. Hennelly KE, Mannix R, Nigrovic LE, et al. Pediatric traumatic brain injury and radiation risks: A clinical decision analysis. J Pediatr 2013;162(2):392-397. https://doi.org/10.1016/.jpeds.2012.07.018

29. Easter JS, Bakes K, Dhaliwal J, Miller M, Caruso E, Haukoos JS. Comparison of PECARN, CATCH, and CHALICE rules for children with minor head injury: A prospective cohort study. Ann Emerg Med 2014;64(2):145-152. https://doi.org/10.1016/j.annemergmed.2014.01.030

30. Burstein B, Upton JE, Neuman MI, Terra F. Use of CT for head trauma: 2007 - 2015. Pediatrics 2018;142(4):e20180814. https://doi.org/10.1542/peds.2018-0814 
31. Mannix R, Meehan WP, Monuteaux MC, Bachur RG. Computed tomography for minor head injury: Variation and trends among major U.S. pediatric emergency departments. J Pediatr 2012;160(1):136139. https://doi.org/10.1016/j.jpeds.2011.06.024

32. Lack V, Esteves M, Uzoma Nnaji L, Loveland JA, Westgarth-Taylor C. The epidemiology of paediatric electrical injuries in a South African township. Burns Open 2020;4(2):53-59. https://doi.org/10.1016/j. burnso.2020.01.001
33. Babikian T, Asarnow R. Neurocognitive outcomes and recovery after pediatric TBI: Meta-analytic review of the literature. Neuropsychology 2009;23(3):283-296. https://doi.org/10.1037/a0015268

Accepted 31 March 2021 